\title{
Contrasting Metacognitive, Social Cognitive and Alexithymia Profiles in Adults with Borderline Personality Disorder, Schizophrenia and Substance Use Disorder
}

Paul H. Lysaker a,b*, Sunita George ${ }^{\mathrm{c}}$, Kelly A. Chaudoin - Patzoldt ${ }^{\mathrm{c}}$, Ondrej Pec ${ }^{\mathrm{d}, \mathrm{e}}$, Petr Bob ${ }^{\mathrm{d}}$, Behtany Leonhardt ${ }^{\mathrm{b}}$, Jenifer L. Vohs ${ }^{\mathrm{b}}$, Alison V. James ${ }^{\mathrm{f}}$, Amanda Wickett-Curtis ${ }^{\mathrm{a}, \mathrm{b}}$, Kelly D. Buck $^{\mathrm{a}}$, and Giancarlo Dimaggio ${ }^{\mathrm{g}}$.

${ }^{\mathrm{a}}$ Richard L. Roudebush VA Medical Center, Day Hospital $116 \mathrm{H}, 1481$ W. $10^{\text {th }}$ Street, Indianapolis, IN 46202, USA

${ }^{\mathrm{b}}$ Department of Psychiatry, Indiana University School of Medicine, $355 \mathrm{~W} .16^{\text {th }}$ Street, Suite 4800, Indianapolis, IN 46202, USA

'School of Psychological Sciences, University of Indianapolis, 1400 East Hanna Avenue, GH109, Indianapolis, IN, 46227, IN, USA

${ }^{\mathrm{d}}$ Center for Neuropsychiatric Research of Traumatic Stress, Department of Psychiatry, First Faculty of Medicine, Charles University, Ovocný trh 3-5, 11636 Praha 1-Staré Město, Prague, Czech Republic

${ }^{\mathrm{e}}$ Psychotherapeutic and Psychosomatic Clinic ESET, Prague, Czech Republic

${ }^{\mathrm{f} D e p a r t m e n t ~ o f ~ P s y c h o l o g y, ~ I n d i a n a ~ S t a t e ~ U n i v e r s i t y, ~ B-207 ~ R o o t ~ H a l l, ~} 200$ N. Seventh Street, Terre Haute, IN 47809, USA

${ }^{g}$ Center for Metacognitive Psychotherapy, Piazza dei Martiri di Belfiore 4, 00195 Rome, Italy

*Corresponding author: Richard L. Roudebush VA Medical Center, Day Hospital 116H, 1481 W. $10^{\text {th }}$ Street, Indianapolis, IN 46202, USA. Email address: plysaker@iupui.edu (PH Lysaker)

\begin{abstract}
Deficits in the ability to recognize and think about mental states are broadly understood to be a root cause of promote dysfunction in Borderline Personality Disorder (PD). This study compared the magnitude of those deficits relative to other serious mental illness or psychiatric conditions. Assessments were performed using the metacognition assessment scale-abbreviated (MAS-A),
\end{abstract}

This is the author's manuscript of the article published in final edited form as:

Lysaker, P. H., George, S., Chaudoin-Patzoldt, K. A., Pec, O., Bob, P., Leonhardt, B., ... Dimaggio, G. (2017). Contrasting Metacognitive, Social Cognitive and Alexithymia Profiles in Adults with Borderline Personality Disorder, Schizophrenia and Substance Use Disorder. Psychiatry Research. https://doi.org/10.1016/j.psychres.2017.08.001 
emotional recognition using the Bell Lysaker Emotional Recognition Test and alexithymia using the Toronto Alexithymia Scale among adults with schizophrenia $(n=65)$, Borderline PD $(n=34)$ and Substance Use disorder without psychosis or significant Borderline traits ( $\mathrm{n}=32)$. ANCOVA controlling for age revealed the Borderline PD group had significantly greater levels of metacognitive capacity on the MAS-A than the schizophrenia group and significantly lower levels than the Substance Use group. Multiple comparisons revealed the Borderline PD group had significantly higher self-reflectivity and awareness of the other's mind than the schizophrenia group but lesser mastery and decentration on the MAS-A than substance use group, after controlling for self-report of psychopathology and overall number of PD traits. The Borderline PD and Schizophrenia group had significantly higher levels of alexithymia than the substance use group. No differences were found for emotion recognition. Results suggest metacognitive functioning is differentially affected in severe mental disorders.

\section{Introduction}

Alterations in the ability to recognize and think about one's own and others' mental states is a hallmark of Borderline Personality Disorder (Borderline PD). Deficits in these abilities, referred to using the related constructs of metacognition (Semerari et al., 2003), social cognition (Roepke et al., 2013) and mentalizing (Bateman and Fonagy, 2004; Fonagy, 1991) have been proposed as underlying causes of many characteristic Borderline PD behaviors including stormy interpersonal relationships, lack of a core sense of identity, affective instability, and chronic failure to effectively respond to psychological and social challenges (Fonagy et al., 2002; Roepke et al., 2013; Semerari et al., 2007). 
Research on metacognition, social cognition and mentalization in Borderline PD includes at least two types of studies. First, research has examined the association of Borderline PD with deficits recognizing different kinds of internal states. This has revealed mixed results. Heightened levels of alexithymia have been found in Borderline PD (Joyce et al., 2013; Lecours and Bouchard, 2011; McMain et al., 2013; Peter et al., 2013) though there have been some failures to replicate this (Nicolò et al., 2011). Difficulties correctly recognizing others' emotions has been found in some but not all studies (Dziobek et al., 2011; Hepp et al., 2016; Lowyck et al., 2016; Niedtfeld et al. 2017). Borderline PD has been more consistently linked with difficulties detecting others' motives especially in complex and emotionally charged situations (Brüne et al., 2016; Ghiassi et al., 2010; Peter et al., 2013; Petersen et al., 2016; Preißler et al., 2010; Sharp et al., 2011). It has also been suggested that patients with Borderline PD tend to over-ascribe mental states to others (Searles, 1996), or hypermentalize (Sharp et al., 2013).

A second group of studies has focused whether there are prominent difficulties forming and using more complex integrated representations about the self and others in Borderline PD (Dimaggio et al., 2007; Ha et al., 2013). Semerari et al. (2005; 2014; 2015) found Borderline PD was less linked to the ability to describe cognitions and emotions, and more closely associated with difficulties forming complex ideas about their own changing mental states within the flow of life. Dimaggio et al. (2009) additionally found Borderline PD patients had unique difficulties seeing how the world could be perceived from the perspective of the other, or adopting a decentered stance. Outcalt et al. (2016) found that deficits in metacognitive mastery, or the ability to use metacognitive knowledge to respond to psychosocial challenges, moderated the relationship of anxious attachment to the severity of symptoms of Borderline PD. It has also been suggested that persons with Borderline PD are generally able to understand both the thoughts and 
feelings of the others, but struggle when situations demand more complex reflections about what is happening within the flow of that situation (Carcione et al., 2011).

Since the earliest work which sought to define the disorder, Borderline PD has been conceptualized as involving disturbances in sense of self and others that are qualitatively different than those found in schizophrenia (Hoch and Polatin, 1949; Stone, 1977). Yet it remains unclear whether the deficits noted in Borderline PD are in fact unique relative to those experienced in schizophrenia, a condition with known metacognitive and social cognitive deficits (Lysaker et al., 2015). There are several reasons to suppose that persons with Borderline PD should have a different pattern of impairment than persons with schizophrenia. First, the presence of different kinds of metacognitive impairments are suggested by the differing form of psychosocial impairment in the two disorders. While in schizophrenia there are more likely to be tenuous social connections, in Borderline PD there are more likely to be stormy and unstable ones. Second, the hypothesized roots of social cognitive and metacognitive dysfunctions are different between the groups. In schizophrenia, anomalous self-experience and neurocognition have been proposed to contribute to these deficits (Lysaker et al., 2013), while disturbances in attachment and the abilities to manage emotion have been proposed as causal factors in Borderline PD (Fonagy et al., 2002). Consistent with this are studies that participants with schizophrenia performed more poorly on Theory of Mind tasks tending to show a lack of mentalization while the errors of participants with Borderline PD were the result of hypermentalizing (Andreou et al.; 2015; Vaskinn et al., 2015). Examining difficulties synthesizing self-experience, Pec et al. (2014) reported that patients with Borderline PD showed slightly different levels of splitting compared to patients with schizophrenia which were linked 
with history of trauma and additionally had unique correlations with dose of antipsychotic medication.

Nevertheless, patients diagnosed with both conditions do experience social alienation, stigma and demoralization (Rüsch et al., 2006), factors that are known to affect the ability to recognize and reason about mental states which they disrupt basic trust and motivation for interpersonal connection. Patients with Borderline PD are also prone to experiencing transient psychotic symptoms. Thus, it essential to investigate whether patients with Borderline PD and schizophrenia do indeed differ in their abilities to think about mental states and if so how.

To explore this issue, the current study compared the abilities of persons with schizophrenia, Borderline PD and substance use disorder to accurately recognize two specific elements of mental states: one's own emotions (alexithymia) and the emotions of others, and to synthesize that information into complex and integrated ideas about the self and others. We selected alexithymia and emotion recognition as both are closely tied to the ability to respond to emergent social experience and have been identified as areas of need in the literature noted above. We chose metacognition as it allows for the separate measurement of self-reflectivity, awareness of other's mental states, decentration and metacognitive mastery, casting each as a spectrum of activities which vary according to the extent by which they are synthesized into complex integrated representations (Lysaker et al., 2013; Semerari et al., 2003). We chose substance use disorder as a third psychiatric condition as it a common comorbidity of Borderline PD linked with deficits in the ability to reflect about mental states (Dimaggio et al., 2015; Morken et al., 2014), including alexithymia (Bashapoor et al., 2015; Taylor et al., 1997) and deficits recognizing the intentions (Maurage et al., 2015) and emotions of others (Nandrino et al., 2014). Of note, work on substance use and social cognition has generally failed to consider the 
potential effects of comorbid PD traits, leaving it unclear to what extent these findings reflect substance use or comorbid Borderline PD traits.

Our primary aim was to test whether persons with Borderline PD performed differently on assessments of alexithymia, emotion recognition and metacognition, relative to persons with schizophrenia and persons with substance use disorder. We made several predictions. First, based upon earlier work (Carcione et al., 2011; Dimaggio et al., 2009; Semerari et al., 2005; 2014; 2015; Outcalt et al., 2016; Semerari, 1999) we predicted that the Borderline PD group's levels of alexithymia and deficits in affect recognition would be less than what is observed in the schizophrenia group but greater than the deficits associated with the substance use group. While previous work has linked substance use disorders to alexithymia and deficits in emotion recognition, that work generally did not account for the presence of Borderline PD traits and hence we reasoned that a substance abuse group that did not include persons with Borderline PD would have less severe overall levels of impairment. Second, we predicted that overall metacognitive capacity of the Borderline PD group would be lesser than the substance use group and higher than the schizophrenia group. Third, we predicted that the Borderline PD group would have lower levels of two specific forms of metacognition: 1) Decentration, and 2) Mastery, the ability to use metacognitive knowledge to respond to stress. We anticipated this metacognitive profile given literature that while many with Borderline PD can make basic guesses about others' emotions, and express their own distress, they may fail to see the perspective of others or use knowledge of themselves when distressed (Caricone et al., 2011; Dimaggio et al., 2009; Outcalt et al. 2016; Sharp et al., 2013).

We also had a secondary and exploratory aim of comparing the strength of the relationships between metacognitive domains across groups. We hypothesized that the 
metacognitive capacities of the schizophrenia group would be more closely related given literature suggesting that metacognitive deficits in schizophrenia are more global and trait like in nature, while in Borderline PD, impairments are hypothesized to be context dependent and responsive to interpersonal factors in the moment (Fonagy et al., 2002; Liotti et al., 2008; Brüne et al., 2016; Ghiassi et al., 2010). Regarding the relationship of different elements of metacognition to one another in the substance use group, we made no predictions but considered those results to offer potential preliminary insights into how different metacognitive dimensions may influence one another or covary.

\section{Method}

\section{1 Participants}

Thirty-four adults who met criteria for Borderline PD, as assessed with Structured Clinical Interview for DSM-IV Axis II Personality Disorders (First et al., 1997), 32 adults with a diagnosis of a Substance Use Disorder and without a diagnosis of a psychotic disorder as per the Structured Interview for DSM-IV Disorders-II (SCID; Spitzer et al., 1994) and 65 adults with the SCID-I confirmed diagnoses of Schizophrenia Spectrum Disorder (Schizophrenia, $n=43$; schizoaffective disorder, $\mathrm{n}=22$ ) were recruited from a VA Medical Center. All participants were receiving ongoing outpatient treatment and were in a post-acute or stable phase of their disorder, defined as no hospitalizations or changes in medication or housing in the last month. Participants were referred by their clinicians. Demographics per group are reported in Table 1.

Participants reported in this study participated in one of three studies. The schizophrenia group was recruited for a study of the effects of cognitive therapy on work outcome. Exclusion criteria in this study included active substance dependence. The Substance Use group was 
recruited for a study of metacognitive correlates of treatment outcome. Exclusion criteria for this study included schizophrenia or bipolar disorder as assessed with the SCID and three or more Borderline PD traits as assessed with the SCID-II. We allowed the substance use group to have two or fewer Borderline PD traits reasoning that these traits are common in substance use and hence to require the presence of no traits might reduce the representativeness of the group. Also, by limiting permissible Borderline PD traits to two or fewer, will prevent the substance use group from being too similar to the Borderline PD group. The Borderline PD participants came from two separate studies which were investigating the metacognitive correlates of personality and attachment $(\mathrm{n}=23)$ and the metacognitive correlates of treatment outcome $(\mathrm{n}=11)$. In these two studies, the only significant methodological difference was that in the latter study comorbid substance use was assessed, and schizophrenia and bipolar disorder were ruled out with the SCID-I, while in the former study substance use was assessed, and schizophrenia and bipolar disorder were ruled out with the Mini International Neuropsychiatric Interview (MINI) (Sheehan et al., 1998). The baseline assessment of the Schizophrenia group did not include the SCID-II nor assessment of current substance use disorders, beyond ruling out current substance dependence.

\subsection{Instruments}

Indiana Psychiatric Illness Interview (IPII; Lysaker et al., 2002) is a semi-structured interview typically lasting 30 to 60 minutes. Responses are audio taped and later transcribed. The interviewer asks participants to discuss: i) the story of their life in general, ii) whether they think they have a mental illness and, if so, the ways that it has affected and not affected their life, iii) how this condition controls and is controlled by them; iv) how it affects, and is affected by others, and v) what they see in the future. The IPII differs from other psychiatric interviews in 
that minimal prompts are introduced and metacognitive capacities appear spontaneously. The IPII does not produce quantitative scores on its own but is one of several sources from which the Metacognition Assessment Scale-Abbreviated can be used to rate metacognition.

\subsubsection{Metacognition Assessment Scale- Abbreviated (MAS-A; Lysaker et al., 2005)}

The MAS-A is a rating scale, adapted from the MAS (Semerari et al., 2003), that assesses synthetic metacognitive capacities or the ability to synthesize discrete pieces of information into an integrated representation. This assessment is rated on the basis of the IPII and produces four scores and a total score which is the sum of those four scores. The first subscale, Selfreflectivity, is a 9-point scale that gauges one's ability to form ideas about oneself in an increasingly plausible and integrated manner. The second subscale, Awareness of the Mind of the Other, is a 7-point scale that assesses one's ability to form ideas about others in an increasingly plausible and complex manner. The third subscale, Decentration, is a 3-point scale that addresses one's ability to form ideas about oneself and others within the context of the larger world. The last subscale, Mastery, is a 9-point scale that assesses one's capacity to use knowledge of oneself and others to respond to psychological and social challenges. For all four scales, higher scores indicate greater capacity for metacognition.

The MAS-A has been found to have good inter-rater reliability with intra-class coefficients ranging from 0.71 to 0.91 (Lysaker at al., 2005). Regarding validity, MAS-A scores have been associated with assessments of awareness of illness, complexity of social schemas, preferences for active coping, and cognitive insight (c.f. Lysaker et al., 2015).

2.2.2 Toronto Alexithymia Scale - 20 (TAS-20; Bagby et al., 1994a)

The TAS-20 is a 20 -item self-report measure of alexithymia. Items are rated using a fivepoint Likert scale, with participants indicating level of agreement with statements that assess 
both the affective and cognitive elements related to recognizing one's own emotions. Total scores range from 20 to 100, with higher scores indicating greater degree of alexithymia. Though the present study analyzed alexithymia as a dimensional construct, it has been suggested that scores exceeding 60 are indicative of clinically significant alexithymia (Taylor and Taylor, 1997). In addition to a total score, the TAS-20 yields three factor scores: difficulty identifying feelings, difficulty describing feelings, and externally-oriented thinking. Evidence of acceptable internal consistency, test-retest reliability, and construct, concurrent, and convergent validity has been reported (Bagby et al., 1994a; 1994b).

2.2.3 Bell-Lysaker Emotional Recognition Task (BLERT; Bell et al., 1997)

The BLERT is a measure of ability to identify affect cues in videotaped stimuli. Participants are presented with 21-videotaped segments and asked to correctly identify the affects portrayed. Data on the adequacy of the BLERTs reliability and validity have been reported elsewhere (Bell et al., 1997; Bryson et al., 1997).

\subsubsection{Symptom Checklist-90-R (SCL-90-R; Derogatis, 1977)}

The SLC-90-R is a 90 item self-report inventory which was primarily designed to reflect the psychological symptom patterns of psychiatric and medical patients. It is a measure of current (state) psychological symptom status. The SCL-90-R measures nine primary symptom dimensions and generates an estimate of global psychopathology. For the purposes of this study we were interested in the score reflective of general psychopathology, the global severity index (GSI). Information regarding reliability including acceptable coefficient alpha have been reported elsewhere (Outcalt et al., 2016).

2.2.5. Mini International Neuropsychiatric Interview (MINI; Sheehan et al., 1998) 
The MINI is a brief structured clinical interview which produces diagnoses of several psychiatric disorders as defined by DSM-IV and ICD-10. For the purposes of this study we sought to rule out the presence of schizophrenia, and bipolar disorder.

\subsection{Procedure}

Institutional research review committees approved all procedures. Following informed written consent, diagnoses were determined using the SCID-I and II or MINI. Participants were administered the IPII, TAS, and BLERT. Participants in these analyses came from three different studies as noted above. Participants in the Borderline PD group and the Substance Use group also completed the SCL-90. Metacognition was rated from a transcription of the IPII using the MAS-A. MAS-A ratings were assessed blind to performance on the BLERT, TAS, SCL-90, and SCID-II.

\subsection{Analyses}

Analyses were performed in five steps. First, we planned to compare the Borderline PD, Substance Use and Schizophrenia Spectrum groups on demographic variables and comorbidities to determine the need for covariates in group comparisons. Second, an analysis of covariance (ANCOVA) was planned to be used to compare the MAS-A, TAS, and BLERT scores, controlling for any necessary covariates. Fisher's Least Squared Differences test were planned to compare individual groups in instances in which there were significant overall group differences noted in the ANCOVA. Third, we planned to compare the SCL-90 GSI scores and overall number of other PD traits on the SCID-II (the total number of traits excluding the borderline traits) of the Borderline PD and Substance Use groups with an ANOVA. Fourth, if there were significant differences on these variables, we planned to repeat the comparisons with another ANCOVA the MAS-A, TAS, and BLERT scores between the Borderline trait group and the 
Substance Use group adding the overall number of other PD traits on the SCID-II (the total number of traits excluding the Borderline traits) and the SCL-90 to rule out the possibility that group differences were merely the result of their having more overall PD traits or their having higher levels of global psychopathology. Finally, we planned to separately correlate the MAS-A subscales with one another. We planned then to compare the average intercorrelations of the MAS-A items between groups using the Fisher $r$ to $z$ transformation.

\section{Results}

As revealed in Table 1, the Substance Use group was significant younger than the Schizophrenia group. Groups did not differ on education, gender, or race. Concerning comorbities, the group with Borderline PD had a median of 6 Borderline and 17 other (nonBorderline) traits on the SCID-P, while the Substance use group had a median of 1 Borderline trait and 8 other (non-Borderline) traits on the SCID-II. Of the 34 participants in the Borderline PD group, 25 had comorbid diagnoses of lifetime substance use disorders. When the types of substance use disorders found in the Substance Use and Borderline PD groups with comorbid substance use were compared, equivalent proportions of participants were found to have specific diagnoses of alcohol use (26/32,79\% and 20/25 80\%) for the Substance Use group and Borderline PD groups respectively), Cannabis (12/32, 38\% and 7/25 28\%) for the Substance Use group and Borderline PD groups, respectively, and Opiate Use disorder (8/32, 25\% and 5/25 $20 \%$ ) for the Substance Use group and Borderline PD groups respectively. There was a significantly greater proportion of cases of cocaine abuse in Substance Use than in the Borderline PD group (15/32, 47\% and 4/25 16\% respectively).

ANCOVA controlling for age were then conducted comparing groups on MAS-A, TAS, and BLERT scores. As revealed in Table 2 the Schizophrenia group had significantly lower 
overall scores on the MAS-A than either of the two other groups. The Borderline PD group had significantly lower MAS-A scores than the Substance Use group. On the MAS-A subscales the Borderline PD and Schizophrenia group had significantly lower Decentration and Mastery scores than the Substance Use groups, while the Borderline PD and Substance Use groups had significantly higher Self-reflectivity and Awareness of the Other compared to the Schizophrenia group. The Borderline PD and Schizophrenia groups additionally had significantly greater scores on the TAS total and all its subscales. No differences were found for the BLERT total.

As revealed in Table 1 the Borderline PD group had significantly more overall PD traits (excluding Borderline PD traits) and higher SCL-90 GSI scores. Previous comparisons in which these groups differed were then repeated as another ANCOVA controlling for overall PD traits (excluding Borderline PD traits) and the SCL-90 GSI. As revealed in Table 2 the groups continued to differ significantly on the MAS-A total, MAS-A Mastery subscale, the TAS total and TAS Identifying feelings subscale.

In the final planned step, we correlated the MAS-A individual scales with one another, and separately for all three groups. The individual correlations are presented in Table 3 . When summed to provide an overall estimate of how closely the scales were related to one another we found an average intercorrelation of 0.24 for the Borderline PD group, 0.29 for the Substance Use group and 0.63 for the Schizophrenia group. Using the Fisher $r$ to $\mathrm{z}$ transformation we found that the average correlation of the Schizophrenia group was significantly greater than that Borderline PD $(z=-2.26, p=0.02)$ and the Substance Use $(z=-1.97, p=0.04)$ groups. The mean intercorrelation of the Substance Use and Borderline PD groups did not differ significantly $(z=0.21, p=\mathrm{ns})$. 
It was unexpected that the Borderline PD and Schizophrenia groups did not differ on the MAS-A Decentration subscale given frequent observations that patients with schizophrenia struggle to achieve any decentration at all. We therefore performed exploratory ad hoc analyses comparing the frequency of the lowest possible score ("0") on Decentration for both groups. This revealed that significantly more participants in the schizophrenia group had scores of " 0 " (30 out of 65 or $46 \%$ ) than participants in the Borderline PD Group (7 out of 34 or $21 \%$; $X^{2}=$ $6.23 ; \mathrm{p}=01)$. By comparison, five of the $32(16 \%)$ members of the Substance Use group also had a score of a "0" on Decentration.

Finally, there was high comorbidity of substance use disorders in the BPD group and to rule out the possibility that this accounted for any observed differences, we conducted $T$-Tests comparing the MAS-A, and TAS scores of those persons in the BPD group with and without a comorbid diagnosis. None of the comparisons were significant.

\section{Discussion}

The study had a primary aim of comparing the levels of metacognitive deficit, alexithymia and emotion recognition of patients with Borderline PD, schizophrenia and others with substance use disorder and a secondary aim to contrast the relationships of individual components of metacognition one another across the different clinical groups. As predicted, we found that the Borderline PD group had less severe impairments in metacognitive function than the Schizophrenia group, and more severe impairments than the group with Substance Use disorders. In contrast to the Schizophrenia group, the Borderline PD group was better able to reflect upon oneself and to make sense of the cognitive and affective functioning of others. In these domains, the ability of patients with Borderline PD were generally in the same range of persons with substance use disorder without significant levels of Borderline PD traits. In contrast 
to the Substance Use disorders group, the Borderline PD group was less able to understand that others view events from a perspective distinct from their own and unrelated to their needs. The Borderline PD group also had more difficulties in using knowledge of mental states for purposeful problem solving. In these domains, Borderline PD patients demonstrated comparable metacognitive capacity to Schizophrenia group. Of note, the global differences in overall index for metacognition and mastery between the Borderline PD and the Substance Use group persisted after controlling for global psychopathology and presence of other PD traits and thus these findings were not merely a reflection of severity of PD or psychopathology. The difference in decentration by contrast was reduced to the level of a trend which suggested that general emotional distress may affect the capacity for decentration in the Borderline PD group.

Although the cross-sectional nature of the data precludes drawing causal conclusions, results are generally consistent with emerging models of Borderline PD which suggest that this condition, relative to at least some other forms of mental disorder, may involve unique difficulties recognizing and thinking about mental states. These may include difficulties integrating information into reflections about the self and others and ultimately translating that information into meaningful action. This is consistent with work which has described how, at the level of content, the fragmentation of sense of self and others differs between persons with Borderline PD and schizophrenia and results in qualitatively different subjective experiences (Pec et al., 2014; Stone, 1977).

Somewhat surprisingly, while the Borderline PD group reported higher levels of alexithymia than the Substance Use disorder group, their reported levels were equivalent to those of the schizophrenia group. Furthermore, there were no overall differences found in affect recognition. This may suggest that there are some social cognitive deficits which are not specific 
to one kind of mental disorder. It may also suggest that other forms of social cognition such as unawareness of one's own affect are equivalently affected in different forms of particularly severe mental illness. Importantly, the global differences in metacognition and alexithymia between the Borderline PD and the Substance Use groups persisted after controlling for global psychopathology and presence of other PD traits and thus this finding was not merely a reflection of severity of PD or psychopathology. This does suggest that the experience of alexithymia in Substance Use disorders may be considerably less than in Borderline PD and Schizophrenia. It also points to the possibility that previous work linking alexithymia with substance use may be partially a function of the presence of co-morbid Borderline PD. Of note, as with all unexpected findings, these interpretations should be taken as speculative and fodder for future research.

Concerning the secondary exploratory aim of the study, which was to compare the relationships of individual components of metacognition with one another, as predicted, we found that the different domains of metacognition were more closely related in the Schizophrenia group relative to the Borderline PD group. This is consistent with the idea that the metacognitive problems in schizophrenia are of a global nature, while in Borderline PD some aspects of metacognition are more intact than others. Mean scores for this group indicated they are able to describe the self and the others' cognitive and affective states and to reflect upon these, but not able to appreciate the perspectives of others (Semerari et al., 2005; 2014; 2015) nor use psychological knowledge for purposeful problem solving. Interestingly, the Substance Use disorder group also demonstrated a pattern relative to the Schizophrenia group, in which the scores of the metacognition scale were less significantly related to one another. 
There are limitations of the study. Participants were mostly men in their 40s and 50's involved in treatment. A different relationship may thus exist with the variables studied here among younger persons with schizophrenia, females, or among persons who decline treatment. Additionally, we used only one measurement of metacognition, alexithymia and emotion recognition, and all measurements occurred at only one point in time. Longitudinal research is necessary given the possibility of fluctuations levels of metacognitive function. Work is also needed to explore the potential effects of gender. Psychiatric history and stigma on these relationships. Additionally, the Substance Use and Borderline PD groups had a significant number of other kinds of PD traits, while the majority of the Borderline PD group had significant levels of other PD traits and more often than not also had a comorbid Substance Use disorder. Future work is needed with persons with Substance Use disorders who do not experience PD traits as well as Borderline PD in the absence of a Substance Use disorder. Work is also needed with healthy controls to examine how impaired subjects in each group were in terms of their metacognitive and social cognitive function relative to others without any form of mental illness. We also did not assess comorbid PD and substance use among the schizophrenia group, a common problem experienced by this group which could influence metacognition and alexithymia. Future work is needed with samples that contain more rarified groups without overlapping personality disorder traits and substance use issues. As all participants were in treatment, results may reflect the effects of treatment or the emotional state associated with help seeking. Finally, we used a specific measure which cued for reflections about life history and mental health concerns. It is possible that the metacognitive function of groups could be different in other interviews which called for greater or lesser degrees of affective involvement. Given observations regarding how qualitatively different the representations of self and others are in 
schizophrenia and Borderline PD (e.g. Freedman, 1980) future research is needed to qualitatively explore differences in representations of self and others.

Taken together, this study, albeit only the start, offers evidence that adults with Borderline PD may experience unique deficits in metacognition. With replication, our findings may have several clinical implications. First, they support the idea that treatment of Borderline PD often needs to support the development of the capacity to reason about mental states (Bateman and Fonagy, 2004). It also is consistent with developing metacognitive interventions for PD more specifically focused on Mastery (Buck et al., in press; Dimaggio et al., 2007; 2015; Livesley, Dimaggio and Clarkin, 2016). It also suggests the need for therapies to move beyond helping persons to merely correctly recognize specific thoughts and feelings and instead to promote the capacity to create a complex and integrated sense of self in the world which may underpin the development of a sense of personal agency (Vohs et al., 2016; Buck et al., in press). 


\section{References}

Andreou, C., Kelm, L., Bierbrodt, J., Braun, V., Lipp, M., Yassari, A. H., Moritz, S., 2015. Factors contributing to social cognition impairment in borderline personality disorder and schizophrenia. Psychiatry Res. 229, 872-879.

Bagby, R. M., Parker, J. D., Taylor, G. J., 1994a. The twenty-item Toronto Alexithymia ScaleI. Item selection and cross-validation of the factor structure. J. Psychosom. Res. 38, 23-32.

Bagby, R. M., Taylor, G. J., Parker, J. D., 1994b. The twenty-item Toronto Alexithymia ScaleII. Convergent, discriminant, and concurrent validity. J. Psychosom. Res. 38, 33-40.

Bashapoor, S., Hosseini-Kiasari, S. T., Daneshvar, S., Kazemi-Taskooh, Z., 2015. Comparing sensory information processing and alexithymia between people with substance dependency and Normal. Addict. Health. 7, 174-183.

Bateman, A. W., and Fonagy, P., 2004. Mentalization-based treatment of BPD. J. Personal. Disord. 18, 36-51.

Bell, M., Bryson, G., and Lysaker, P., 1997. Positive and negative affect recognition in schizophrenia: a comparison with substance abuse and normal control subjects. Psychiatry Res. 73, 73-82. 
Brüne, M., Walden, S., Edel, M., Dimaggio, G., 2016. Mentalization of complex emotions in borderline personality disorder: The impact of parenting and exposure to trauma on the performance in a novel cartoon-based task. Compr. Psychiatry. 64, 29-37.

Bryson, G., Bell, M., Lysaker, P.H., 1997. Affect recognition in schizophrenia: a function of global impairment or a specific cognitive deficit. Psychiatry Res. 71, 105-113.

Buck, K.D., Vertinski, M., Kukla, M. Metacognition and Reflection Insight Therapy: Application to a long-term therapy case of borderline personality disorder. In press. Am. J. Psychother.

Carcione, A., Nicolò, G., Pedone, R., Popolo, R., Conti, L., Fiore, D., et al., 2011. Metacognitive mastery dysfunctions in personality disorder psychotherapy. Psychiatry Res. 190, 60-71.

Derogatis, L.R., 1977. SCL-90-R: Administration, Scoring and Procedures Manual-I for the R(revised) Version. Johns Hopkins University School of Medicine, Baltimore.

Dimaggio, G., Carcione, A., Nicolo, G., Conti, L., Fiore, D., Pedone, R., et al 2009. Impaired decentration in personality disorder: a series of single cases analysed with the Metacognition Assessment Scale. Clin. Psychol. Psychother. 16, 450-462. 
Dimaggio, G., D'Urzo, M., Pasinetti, M., Salvatore, G., Lysaker, P.H., Catania, D. et al, 2015. Metacognitive Interpersonal Therapy for Co-Occurrent Avoidant Personality Disorder and Substance Abuse. J. Clin. Psychol. 71, 157-166.

Dimaggio, G., Lysaker, P.H. (Eds.), 2010. Metacognition and severe adult mental disorders: From research to treatment. New York, NY: Routledge.

Dimaggio, G., Semerari, A., Carcione, A., Nicolò, G., Procacci, M., 2007. Psychotherapy of personality disorders: Metacognition, states of mind and interpersonal cycles. New York, NY: Routledge/Taylor and Francis Group.

Dziobek, I., Preißler, S., Grozdanovic, Z., Heuser, I., Heekeren, H. R., Roepke, S., 2011. Neuronal correlates of altered empathy and social cognition in borderline personality disorder. Neuroimage. 57, 539-548.

First, M. B., Gibbon, M., Spitzer, R. L., Williams, J. B. W., Benjamin, L.S., 1997. Structured Clinical Interview for DSM-IV Axis II Personality Disorders, (SCID-II). Washington: American Psychiatric Press, Inc.

Freedman, N., 1980. On splitting and its resolution. Psychoanal. Contemp. Thought. 3, 237-266.

Fonagy, P., 1991. Thinking about thinking: Some clinical and theoretical considerations in the treatment of a borderline patient. Int. J. Psychoanal. 72, 639-656. 
Fonagy, P., 2002. Affect Regulation, Mentalization, and the Development of the Self. New York, NY: Other Press.

Ghiassi, V., Dimaggio, G., Brüne, M., 2010. Dysfunctions in understanding other minds in borderline personality disorder: A study using cartoon picture stories. Psychother. Res. 20, 657667.

Ha, C., Sharp, C., Ensink, K., Fonagy, P., Cirino, P., 2013. The measurement of reflective function in adolescents with and without borderline traits. J. Adolesc. 36, 1215-1223.

Hepp, J., Hilbig, B. E., Kieslich, P. J., Herzog, J., Lis, S., Schmahl, C. et al. 2016. Borderline Personality and the Detection of Angry Faces. PloS. One. 11, e0152947.

Hoch, P., Polatin, P. 1949. Pseudoneurotic forms of schizophrenia. Psychiat. Quarterly. 23, 248276.

Joyce, A.S., Fujiwara, E., Cristall, M., Ruddy, C., Ogrodniczuk, J. S., 2013. Clinical correlates of alexithymia among patients with personality disorder. Psychother. Res. 23, 690-704.

Lecours, S., Bouchard, M.A., 2011. Verbal elaboration of distinct affect categories and BPD symptoms. Psychol. Psychother. 84, 26-41. 
Livesley, W.J., Dimaggio, G., Clarkin, J.F., 2016. Integrated treatment for personality disorder: A modular approach. New York, NY: Guilford Press.

Liotti, G., Cortina, M., Farina, B., 2008. Attachment theory and multiple integrated treatments of borderline patients. J. Am. Acad. Psychoanal. Dyn. Psychiatry. 36, 295-315.

Lowyck, B., Luyten, P., Vanwalleghem, D., Vermote, R., Mayes, L. C., Crowley, M. J., 2016. What's in a face? Mentalizing in borderline personality disorder based on dynamically changing facial expressions. Personal. Disord. 7, 72-79.

Lysaker, P. H., Carcione, A., Dimaggio, G., Johannesen, J. K., Nicolò, G. et al. 2005. Metacognition amidst narratives of self and illness in schizophrenia: associations with neurocognition, symptoms, insight and quality of life. Acta. Psychiatr. Scand. 112, 64-71.

Lysaker, P. H., Clements, C. A., Plascak-Hallberg, C. D., Knipscheer, S. J., Wright, D. E., 2002. Insight and personal narratives of illness in schizophrenia. Psychiatry. 65, 197-206.

Lysaker, P. H., Vohs, J. L., Ballard, R., Fogley, R., Salvatore, G., Popolo, R., Dimaggio, G., 2013. Metacognition, self-reflection and recovery in schizophrenia. Futur. Neuro. 8, 103-115.

Lysaker, P.H., Vohs, J., Minor, K.S., Irarrázaval, L., Leonhardt, B., Hamm, J.A. et al., 2015. Metacognitive deficits in schizophrenia: Presence and associations with psychosocial outcomes. J Nerv. Ment. Dis. 203, 530-536. 
Maurage, F., Timary, P., Tecco, J. M., Lechantre, S., Samson, D., 2015. Theory of mind difficulties in patients with alcohol dependence: beyond the prefrontal cortex dysfunction hypothesis. Alcohol. Clin. Exp. Res. 39, 980-988.

McMain, S., Links, P. S., Guimond, T., Wnuk, S., Eynan, R., Bergmans, Y. et al. 2013. An exploratory study of the relationship between changes in emotion and cognitive processes and treatment outcome in borderline personality disorder. Psychother. Res. 23, 658-673.

Morken, K., Karterud, S., Arefjord, N., 2014. Transforming disorganized attachment through mentalization-based treatment. J. Contemp. Psychother. 44, 117-126.

Nandrino, J. L., Gandolphe, M. C., Alexandre, C., Kmiecik, E., Yguel, J., Urso, L., 2014. Cognitive and affective theory of mind abilities in alcohol-dependent patients: The role of autobiographical memory. Drug Alcohol Depend. 143, 65-73.

Nicolò, G., Semerari, A., Lysaker, P. H., Dimaggio, G., Conti, L., D'Angerio, S. et al. 2011. Alexithymia in personality disorders: Correlations with symptoms and interpersonal functioning. Psychiatry Res. 190, 37-42.

Niedtfeld, I., Defiebre, N., Regenbogen, C., Mier, D., Fenske, S., Kirsch, P., et al. 2017. Facing the problem: Impaired emotion recognition during multimodal social information processing in borderline personality disorder. J. Pers. Disord. 31, 273-288. 
Outcalt, J., Dimaggio, G., Popolo, R., Buck, K., Chaudoin-Patzoldt, K. A., Kukla, M. et al. 2016. Metacognition moderates the relationship of disturbances in attachment with severity of borderline personality disorder among persons in treatment of substance use disorders. Compr. Psychiatry. 64, 22-28.

Pec, O., Bob, P., Raboch, J., 2014. Dissociation in schizophrenia and borderline personality disorder. Neuropsychiatr. Dis. Treat. 10, 487-491.

Peter, M., Schuurmans, H., Vingerhoets, A. J., Smeets, G., Verkoeijen, P., Arntz, A., 2013. Borderline personality disorder and emotional intelligence. J. Nerv. Ment. Dis. 201, 99-104.

Petersen, R., Brakoulias, V., Langdon, R., 2016. An experimental investigation of mentalization ability in borderline personality disorder. Compr. Psychiatry. 64, 12-21.

Preißler, S., Dziobek, I., Ritter, K., Heekeren, H. R., Roepke, S., 2010. Social cognition in borderline personality disorder: evidence for disturbed recognition of the emotions, thoughts, and intentions of others. Front. Behav. Neurosci. 4, 182.

Roepke, S., Vater, A., Preißler, S., Heekeren, H. R., Dziobek, I., 2013. Social cognition in borderline personality disorder. Front. Behav. Neurosci. 6, 195. 
Rüsch, N., Hölzer, A., Hermann, C., Schramm, E., Jacob, G. A., Bohus, M. et al. 2006. Selfstigma in women with borderline personality disorder and women with social phobia. J .Nerv. Ment. Dis. 194, 766-773.

Searles, H. F., 1996. Countertransference and related subjects. New York: International Universities Press.

Semerari, A., 1999. Cognitive psychotherapy of a serious patient: Metacognition and therapeutic relationship. Millan: Raddaello Cortina.

Semerari, A., Carcione, A., Dimaggio, G., Falcone, M., Nicolo, G., Procacci, M. et al. 2003. How to evaluate metacognitive functioning in psychotherapy? The metacognition assessment scale and its applications. Clin. Psychol. Psychother. 10, 238-261.

Semerari, A., Carcione, A., Dimaggio, G., Nicolò, G., Pedone, R., Procacci, M., 2005.

Metarepresentative functions in borderline personality disorder. J. Pers. Discord. 19, 690-710.

Semerari, A., Carcione, A., Dimaggio, G., Nicolò, G., Procacci, M., 2007. Understanding minds:

Different functions and different disorders? The contribution of psychotherapy research. Psychother. Res. 17, 106-119.

Semerari, A., Colle, L., Pellecchia, G., Buccione, I., Carcione, A., Dimaggio, G., et al. 2014. Metacognition: Severity and styles in personality disorders. J. Pers. Disord. 28, 751-766. 
Semerari, A., Colle, L., Pellecchia, G., Carcione, A., Conti, L., Fiore, D. et al 2015. Personality Disorders and Mindreading. J. Nerv. Ment. Dis. 203, 626-631.

Sharp, C., Ha, C., Carbone, C., Kim, S., Perry, K., Williams, L., Fonagy, P., 2013. Hypermentalizing in adolescent inpatients: treatment effects and association with borderline traits. J. Nerv. Ment. Dis. 27, 3-18.

Sharp, C., Pane, H., Ha, C., Venta, A., Patel, A.B. Sturek, J., et al. 2011. Theory of mind and emotion regulation difficulties in adolescents with borderline traits. J. Am. Acad. Child Adolesc. Psychiatry. 50, 563-573.

Sheehan, D.V., Lecrubier, Y., Sheehan, K.H., Amorim, P., Janavs, J., Weiller, E. et al. 1998. The Mini-International Neuropsychiatric Interview (M.I.N.I): The development and validation of a structured diagnostic psychiatric interview for DSM-IV and ICD-10. J. Clin. Psychiatry. 59, 2233.

Spitzer, R., Williams, J., Gibbon, M., 1994. Structured Clinical Interview for DSM-IV. New York: Biometrics Research.

Stone, M. H., 1977. The borderline syndrome: Evolution of the term, genetic aspects, and prognosis. Am. J. Psychother. 31, 345-365. 
Taylor, G.J., Taylor, H.L., 1997. Alexithymia, in: McCallum, M., Piper, W.E. (Eds.),

Psychological Mindedness: A Contemporary Understanding. Lawrence Erlbaum Associates, Publishers, Mahwah, NJ, pp. 77-104.

Taylor, G. J., Bagby, R. M., Parker, J. A., 1997. Disorders of affect regulation: Alexithymia in medical and psychiatric illness. New York, NY: Cambridge University Press.

Vaskinn, A., Antonsen, B. T., Fretland, R. A., Dziobek, I., Sundet, K., Wilberg, T., 2015. Theory of mind in women with borderline personality disorder or schizophrenia: Differences in overall ability and error patterns. Front. Psychol. 6.

Vohs, J.L., Leonhardt, B.L., 2016. Metacognitive Reflection and Insight Therapy for borderline personality disorder: A case illustration of an individual in a long term institutional setting. J. Contemp. Psychother. 46, 255-264.

Table 1 Comparisons of demographics, personality disorder traits and overall symptom severity

1

Borderline

Substance

Personality Use
Schizophren

ia

3

F

Post Hoc

Compariso

ns

Spectrum
$P<0.05$ 


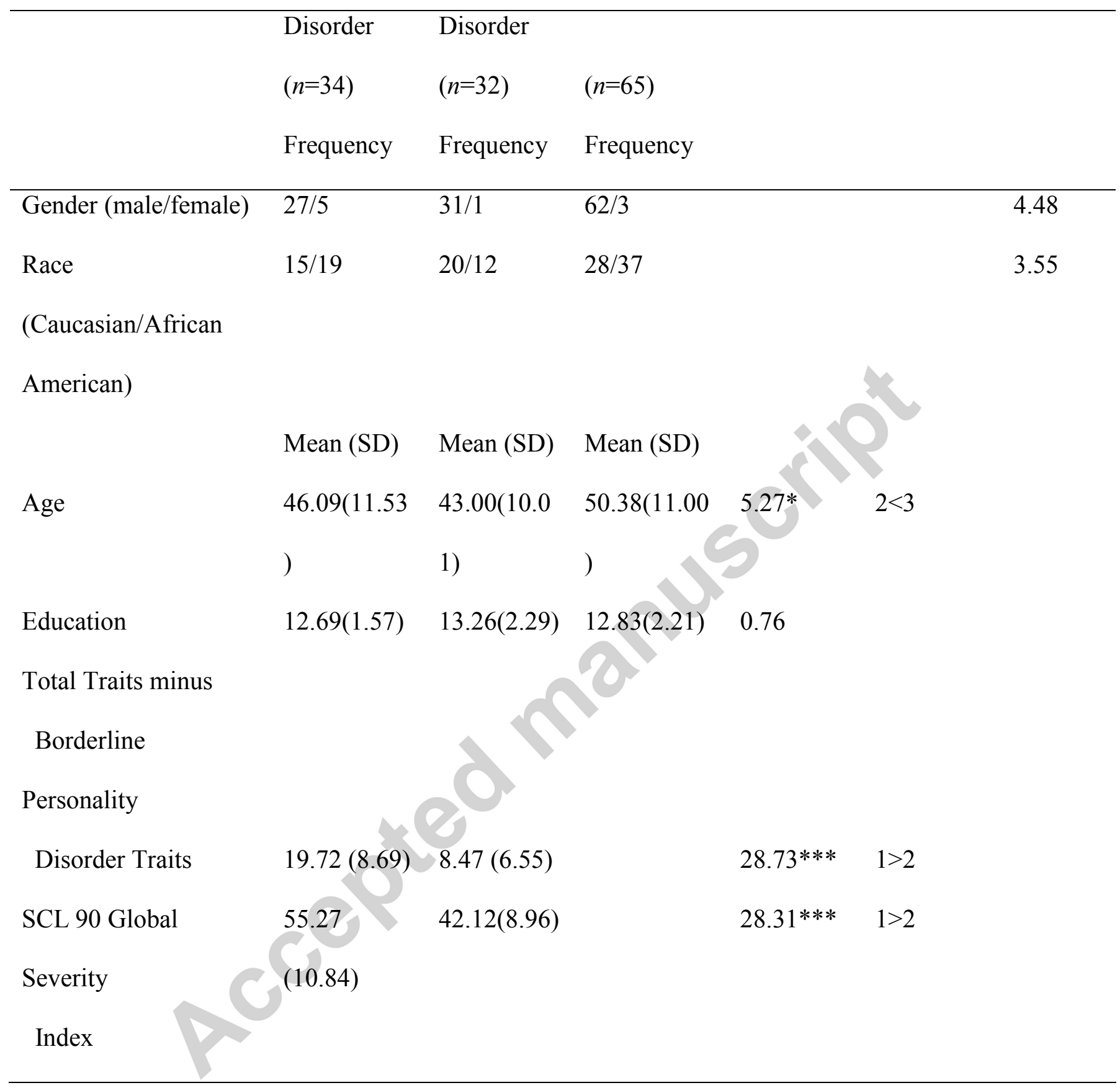

${ }^{*} P<0.05 ; * * * P<0.001$ 
Table 2 Comparisons of metacognition, alexithymia, and affect recognition

\begin{tabular}{|c|c|c|c|c|c|c|}
\hline & & 1 & 2 & 3 & $F$ & Post Hoc \\
\hline & & Borderline & Substance & Schizophrenia & ANCOVA & Comparisons \\
\hline & & Personality & Use & Spectrum & $F(2,128)=$ & $P<0.05$ \\
\hline & & Disorder & Disorder & & & \\
\hline & & $(n=34)$ & $(n=32)$ & $(n=65)$ & & \\
\hline & & Mean $(S D)$ & Mean $(S D)$ & Mean $(S D)$ & & \\
\hline MAS-A & Self- & $5.72(1.66)$ & $6.28(1.63)$ & $4.32(1.46)$ & $15.39 * * *$ & $2,1>3$ \\
\hline & reflectivity & & & & & \\
\hline & Awareness & $3.75(0.94)$ & $4.12(1.02)$ & $2.78(0.91)$ & $23.70^{* * *}$ & $2,1>3$ \\
\hline & of other & & & & & \\
\hline & Decentration & $0.73(0.50)$ & $1.42(1.32)$ & $0.52(0.54)$ & $10.86^{* * *}$ & $2>1,3$ \\
\hline & Mastery & $3.71(1.38)$ & $4.50(1.18)$ & $3.52(1.69)$ & $3.65^{*}$ & $2>1,3^{1}$ \\
\hline & Total & $13.85(3.09)$ & $16.40(3.53)$ & $11.16(4.20)$ & $18.99 * * *$ & $2>1>3^{1}$ \\
\hline TAS & Describing & $16.44(3.97)$ & $13.33(5.53)$ & $15.49(3.82)$ & $4.50^{*}$ & $2<1,3$ \\
\hline & Feelings & & & & & \\
\hline & Identifying & $22.94(5.89)$ & $13.44(6.72)$ & $20.38(6.30)$ & $19.17 * * *$ & $2<1,3^{1}$ \\
\hline & Feeling & & & & & \\
\hline & Externally & & & & & \\
\hline & Oriented & & & & & \\
\hline & Thinking & 21.11 & $17.97(4.66)$ & $22.14(3.61)$ & $9.88^{* *}$ & $2<1,3$ \\
\hline & & $(4.31)$ & & & & \\
\hline & Total & 60.60 & 44.43 & $58.00(11.85)$ & $17.80^{* * *}$ & $2<1,3^{1}$ \\
\hline
\end{tabular}




\section{(10.58) (12.68)}

BLERT

14.67

$15.12(2.62)$

$13.34(3.57)$

1.54

ns

Total

(3.96)

${ }^{*} P<0.05 ;{ }^{*} P<0.001 ; * * * P<0.001 ;{ }^{1}$ post hoc comparisons between groups 1 and 2 remained significant at the 0.05 level after controlling for GSI $T$ score and total number of personality disorder traits 
Table 3 Correlations among MAS-A scales between the three groups

\begin{tabular}{|c|c|c|c|c|c|c|c|c|c|c|c|c|}
\hline & \multicolumn{3}{|c|}{$\begin{array}{l}\text { Borderline PD } \\
(n=34)\end{array}$} & & \multicolumn{4}{|c|}{ Substance Use } & \multicolumn{4}{|c|}{ Schizophrenia Spectrum } \\
\hline MA & $\mathrm{S}$ & $\mathrm{O}$ & $\mathrm{D}$ & $\mathrm{M}$ & $\mathrm{S}$ & $\mathrm{O}$ & $\mathrm{D}$ & $\mathrm{M}$ & $\mathrm{S}$ & $\mathrm{O}$ & $\mathrm{D}$ & $\mathrm{M}$ \\
\hline \multicolumn{13}{|l|}{ S-A } \\
\hline \multicolumn{13}{|l|}{ Scal } \\
\hline \multicolumn{13}{|l|}{ es } \\
\hline $\mathrm{S}$ & - & 0.41 & 0.34 & $0.36^{*}$ & - & $0.51^{* *}$ & $0.41^{*}$ & 0.13 & - & & 0.65 & $0.57^{* *}$ \\
\hline & & $*$ & & & & & & & & & $* *$ & \\
\hline $\mathrm{O}$ & - & - & 0.44 & -0.11 & - & - & $0.36^{*}$ & 0.13 & - & - & 0.78 & $0.60 * *$ \\
\hline & & & $*$ & & & & & & & & $* *$ & \\
\hline $\mathrm{D}$ & - & - & - & 0.02 & - & - & & 0.22 & - & - & - & $0.54 * *$ \\
\hline M & - & - & - & - & - & 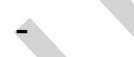 & & - & - & - & - & - \\
\hline
\end{tabular}

$\mathrm{S}=$ Self Reflectivity; $\mathrm{O}=$ Awareness of the mind of the other; $\mathrm{D}=$ Decentration; $\mathrm{M}=$ Mastery; $* P<0.05 ; * * P<0.01$ 


\section{Highlights}

- It is unknown how metacognitive deficits in Borderline Personality Disorder differ from those in schizophrenia

- This study compared metacognition and social cognition among adults with schizophrenia, Borderline Personality Disorder and Substance Use disorders

- Borderline Personality Disorder displayed a unique pattern of metacognitive deficits.

- The Borderline Personality Group had greater deficits in decentration and mastery relative to reflectivity about the self and others. 